\title{
Neuroendocrine control of milk ejection
}

\author{
D. W. Lincoln and A. C. Paisley \\ Department of Anatomy, The Medical School, University of Bristol, University Walk, \\ Bristol BS8 1TD, U.K.
}

\section{Introduction}

The mammary glands of mammals from the platypus to man are identical in fine structure, and consist of alveolar tissue within which milk is continuously secreted during lactation. An alveolar structure increases enormously (perhaps by 10000 -fold) the surface area for secretion relative to the external size of the gland, but at the same time complicates the problem of milk removal. Small ducts generate substantial surface tension forces that oppose the movement of fluids: suction is therefore a relatively ineffective method for removal of alveolar milk. The problem has been overcome by investing the alveoli in a basket-like reticulum of myoepithelium which contracts in response to oxytocin released from the posterior pituitary. When stimulated by oxytocin the alveoli are compressed and milk is expelled into the larger collecting ducts for removal by the sucking of the young. Further, the establishment of a nervous link between the nipple and the oxytocinergic neurones of the hypothalamus allows milk ejection from the alveolar tissue to be co-ordinated with the sucking of the young. Thus is formed the most classical of neuroendocrine reflexes. Our analysis of this reflex would, if we adopted a traditional approach, commence with the sensory input to the hypothalamus (afferent limb) and conclude with a study of the motor response, i.e. the release of oxytocin and milk ejection (efferent limb). There are however sound reasons for reversing this procedure. The process of milk ejection is remarkably uniform in all mammals, but the same cannot be said of the afferent limb of the reflex arc. Two of the laboratory animals make a good comparison in this respect (Text-fig. 1).

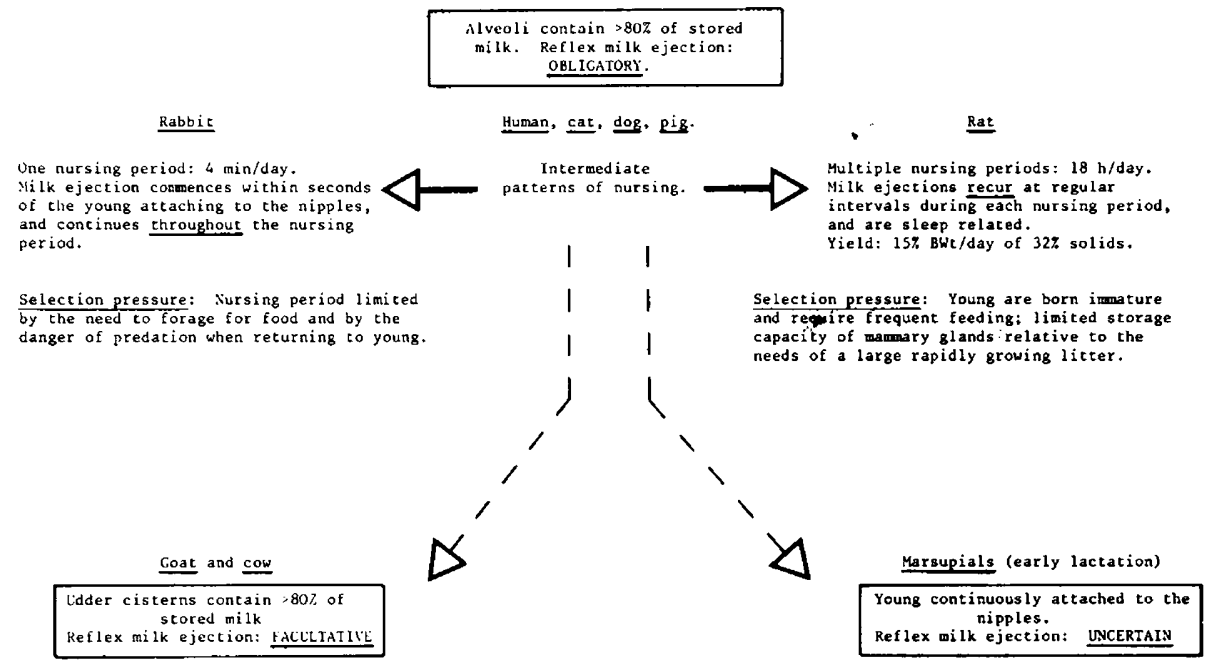

Text-fig. 1. A scheme illustrating variations in the pattern of lactation, nursing behaviour and milk ejection in mammals. 
The rat spends about $18 \mathrm{~h} /$ day during lactation with young firmly attached to her nipples. Individual milk ejections, each lasting about $15 \mathrm{sec}$, are observed at regular intervals of 3-10 min during each nursing period (Text-fig. 2). The rabbit, by contrast, nurses her young for a precise period of 3-4 min once a day.

\section{Milk ejection from the mammary gland}

The contraction of the myoepithelial cell probably involves an oxytocin receptor-mediated depolarization of the cell membrane. During pregnancy the number of receptors in the mammary tissue of the rat increases progressively and remains relatively constant throughout lactation (Soloff, Alexandrova \& Fernstrom, 1979). This contrasts markedly with the uterus where oxytocin receptors in the myometrium increase about 40 -fold in the hours immediately before parturition and rapidly disappear thereafter. These changes in receptor concentration in the uterus are related to dramatic changes in oestrogen, progesterone and prostaglandin production at the time of parturition (Alexandrova \& Soloff, 1980: McCracken, 1980), though clearly the interaction is largely tissue specific and does not involve the mammary gland to any significant degree. One important consequence of these changes in receptor availability, when combined with the fact that copious milk production does not occur until shortly after parturition, is that oxytocin may be used sequentially, first to facilitate the delivery of the young and then later to promote milk ejection. The oxytocin receptors of the mammary gland are not notably specific. Vasopressin, the other major hormone of the posterior pituitary, has $25 \%$ of the milk-ejecting activity of oxytocin in the rat (Berde \& Boissonnas, 1968). This is of some practical importance because it confers on vasopressin, normally released in response to dehydration and increased plasma osmolarity, the potential to influence the contractile activity of the myoepithelium.

The dose-response curve of the mammary gland has a very limited dynamic range when measured in terms of intramammary pressure recorded from a cannulated galactophore. A bolus injection of $0.1 \mathrm{mU}$ oxytocin $(0.2 \mathrm{ng})$ given intravenously to a lactating rat normally fails to procure an increase in intramammary pressure, whereas an injection of $1.0 \mathrm{mU}$ evokes an increase in pressure commencing after a latency of $10 \mathrm{sec}$ and peaking at $8-10 \mathrm{mmHg}$ after 15 sec. Increasing further the size of the injection results in little additional increase in pressure, though at much larger doses $(>5 \mathrm{mU}$ ) multiple contractions may develop (Lincoln, Hill \& Wakerley, 1973). The speed of the injection is also critical. A bolus injection of $0.5 \mathrm{mU}$ delivered in $2 \mathrm{sec}$ will evoke a substantially larger rise in intramammary pressure than $2.0 \mathrm{mU}$ given over $30 \mathrm{sec}$. These results clearly suggest that a pulsatile pattern of hormone release would be the most effective way of utilizing oxytocin to produce milk ejection. Our information for other species is less detailed but supports the point made above. In larger species the response of the mammary gland appears to be more prolonged and it therefore becomes more difficult to correlate contractions with plasma levels of oxytocin. Our studies of the agile wallaby, Macropus agilis, illustrate the situation most clearly (Lincoln \& Renfree, 1981a, b). A bolus injection of 2-30 mU oxytocin (i.v.) causes an increase in intramammary pressure which starts after $25-60 \mathrm{sec}$ and peaks at $30-60 \mathrm{mmHg}$ about $30 \mathrm{sec}$ later. Thereafter the pressure wave decays, although baseline pressure may not be reached for 3-5 min (Text-fig. 5).

The interpretation of intramammary pressure recordings is complicated by three other factors.

Down-regulation. In the rat, the amplitude of the mammary contraction evoked by a second oxytocin injection is substantially reduced if given within $2 \mathrm{~min}$ of a previous injection, suggesting a lack of available receptors. Vasopressin can substantially attenuate the response to an injection of oxytocin (Lincoln \& Renfree, 1981b), indicating that vasopressin binds to the oxytocin receptor, although having a relatively poor ability to elicit a contractile response. In 
physiological terms, therefore, if pulses of oxytocin are released from the posterior pituitary of the rat at intervals of less than 2 min then their efficiency in evoking milk ejection will be diminished.

Multiple contractions. Rhythmic increases in intramammary pressure of decreasing amplitude are usually observed following the injection of large amounts of oxytocin (Cobo, De Bernal, Gaitan \& Quintero, 1967; Lincoln et al., 1973) (Text-figs 2, 4 and 5). One explanation is that vascular stasis at the peak of the mammary contraction limits further access of oxytocin to the myoepithelium, and thus a series of oscillations in contractile activity develop as the amount of oxytocin reaching the myoepithelium waxes and wanes. An alternative explanation is that these contractions relate to a cyclic change in electrical excitability in the myoepithelium itself. Multiple contractions of a continuing nature are recorded during mammary engorgement. The individual waves within such a period of activity are not driven by discrete episodes of oxytocin release, because contractions of adjacent glands are not synchronized. The trigger for the onset of this activity is probably alveolar distension though low levels of oxytocin or even vasopressin might enhance such activity.

Peripheral adrenergic inhibition. Circulating adrenaline, acting on $\beta$-adrenoceptors in the mammary gland, readily blocks the contractile response normally evoked by oxytocin (Cross, 1955; Bisset, Clark \& Lewis, 1967; Vorherr, 1971). However, this inhibition would appear to be of little physiological importance. Circumstances severe enough to cause the release of adrenaline also abolish the release of oxytocin from the posterior pituitary by an inhibitory mechanism expressed within the nervous system (see later discussion).

\section{Measurement of intramammary pressure and plasma levels of oxytocin during nursing}

There are two conflicting problems in attempting to measure intramammary pressure during nursing. Studies of the conscious animal are handicapped because the cannulation procedures invariably cause sufficient stress to block the milk ejection reflex, whilst anaesthetic agents and/or the state of anaesthesia also inhibit the reflex in most species. However, the laboratory rat, when anaesthetized to a depth that permits surgery, readily milk ejects in response to the sucking of her young. The pattern of milk ejection is quite complex. Abrupt rises in intramammary pressure, each lasting about $15 \mathrm{sec}$, recur at regular intervals of 3-10 min throughout each nursing period (Text-fig. 2) (Wakerley \& Lincoln, 1971). Individual contractions correspond closely to contractions elicited by bolus injections of $0.5-1.0 \mathrm{mU}$ oxytocin (i.v.). Increasing the number of young attached to the nipples from 8 to 12 does not change the frequency with which milk ejections recur, though they cease altogether if the number is reduced below 6 . Coincident with the rise in intramammary pressure at each milk ejection the young suck with increased vigour and display extension of their limbs (the stretch reaction) (Vorherr, Kleeman \& Lehmen, 1967). However, it is most important to appreciate that this response of the young follows - albeit within a fraction of a second - the rise in intramammary pressure (Text-fig. 3). Between milk ejections the young rest quietly but remain firmly attached to the nipples. There have been no detailed studies of intramammary pressure in the unanaesthetized rat, but behavioural responses identical to those described above are observed from the young at regular intervals during nursing (Lincoln et al., 1980; Summerlee \& Lincoln, 1981) (Text-fig. 7). These recordings of intramammary pressure suggest a pulsatile pattern of oxytocin release. Furthermore, the periodicity is such that the sensitivity of the mammary gland to oxytocin is maintained. The actual pattern of oxytocin release has not been successfully analysed by the radio-immunoassay of plasma. Such an approach has been prevented by relatively insensitive assays and the need to withdraw large volumes of blood $(1 \mathrm{ml})$ at prescribed times relative to the release of oxytocin. Individual milk ejections are not associated with increases in the plasma level of vasopressin, although the basal level of vasopressin increases from $1.55 \pm 0.34 \mu \mathrm{U} / \mathrm{ml}$ plasma before the application of the young to $2.94 \pm 0.35 \mu \mathrm{U} / \mathrm{ml}$ 
during the period of nursing (D. W. Lincoln \& M. L. Forsling, unpublished observations). This eliminates vasopressin as a causal factor in milk ejection in the rat, and confirms evidence obtained in other species which shows that suckling is a highly selective stimulus for the release of oxytocin (Bisset, Clark \& Haldar, 1970; Legros, Reynaert \& Peeters, 1974).
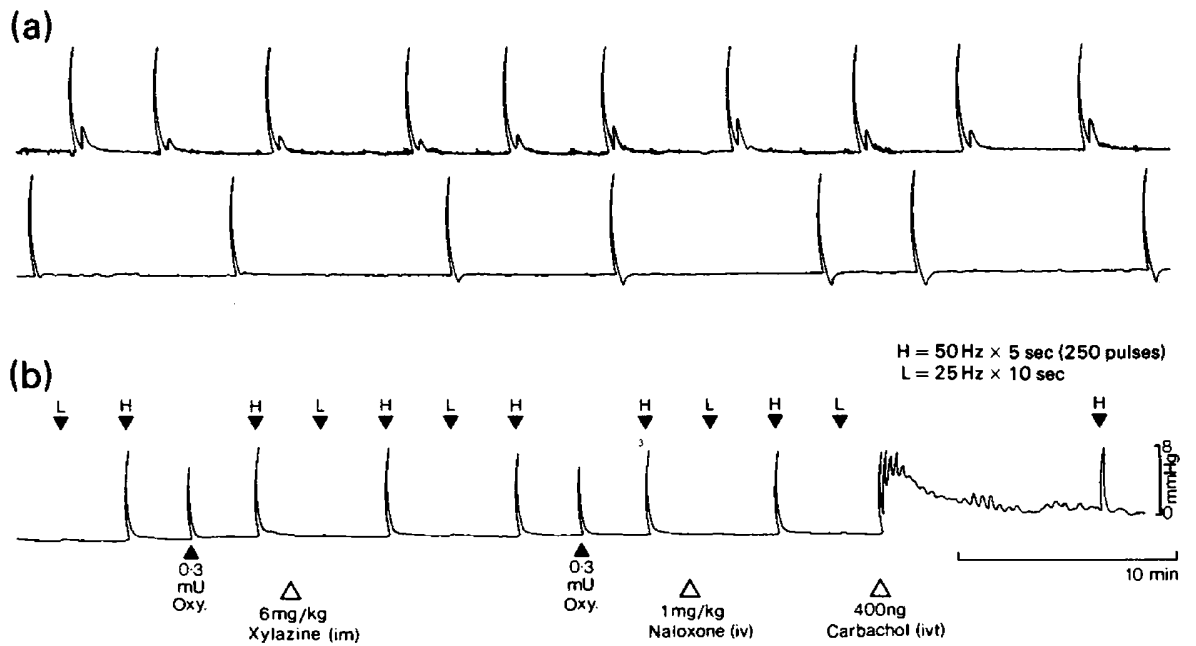

Text-fig. 2. Recordings of intramammary pressure from cannulated galactophores of anaesthetized lactating rats. (a) Recordings from 2 rats anaesthetized with diazepam $(6 \mathrm{mg} / \mathrm{kg}$, i.m.) and xylazine $(6 \mathrm{mg} / \mathrm{kg}, \mathrm{i} . \mathrm{m}$.) to illustrate the pattern of milk ejection evoked by the sucking of the young. Abrupt increases in pressure recurred at intervals of 3-10 min, although 11 young remained attached to the nipples of each mother throughout. (b) A recording from a rat anaesthetized with urethane $(1.2 \mathrm{~g} / \mathrm{kg}$, i.p.) to illustrate the milk ejection response elicited by electrical stimulation of the posterior pituitary with 250 pulses (1 $\mathrm{msec}$ biphasic square waves) delivered at high $(\mathrm{H})$ and low frequencies $(\mathrm{L})$. Stimulation at $25 \mathrm{~Hz}$ was totally ineffective. Xylazine was given to promote analgesia and naloxone to counteract endogenous opioid peptides: neither had any effect on the intramammary pressure response to electrical stimulation or injection of exogenous oxytocin. The intraventricular (ivt) injection of carbachol, a cholinomimetic, evoked a sustained release of oxytocin.

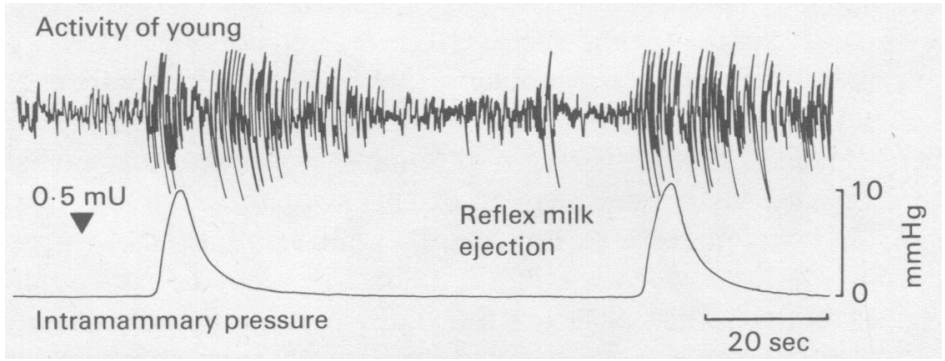

Text-fig. 3. A recording of the movement activity of a litter of rat young during their sucking of an anaesthetized lactating mother. Activity of the young was monitored by radar (see Lincoln $e t$ $a l ., 1980$ ) and plotted alongside a simultaneous recording of intramammary pressure. A vigorous increase in activity was observed coincident with the rise in intramammary pressure at milk ejection. After the initial surge of activity there was a hiatus during which the young sucked with vigour but moved little. With the fall in intramammary pressure much activity was recorded as some young detached themselves and went in search of a more promising nipple at which to feed.

In an elegant study, Cobo et al. (1967) recorded intramammary pressure from a cannulated galactophore in the human breast whilst a baby was placed to suck at the nipple of the opposite gland. Multiple pressure waves of an almost continuous nature were recorded with pressure 
peaks at intervals of 1-2 min (Text-fig. 4). Various attempts were made to simulate these contractions by the intravenous injection of oxytocin. Whilst infusions of $4 \mathrm{mU}$ oxytocin/min and bolus injections of $70 \mathrm{mU}$ evoked multiple contractions with a periodicity similar to that during nursing, the most satisfactory simulation of the suckling-induced phenomenon was obtained with bolus injections of $20-30 \mathrm{mU}$ given at intervals of about $2 \mathrm{~min}$. When serial blood samples were taken during breast feeding oxytocin levels rose within 2 min and peaked after 10 $\mathrm{min}$ at $50-60 \mathrm{pg} / \mathrm{ml}$ (Text-fig. 4) (Dawood, Khan-Dawood, Wahi \& Fuchs, 1981). Superficially these measurements of oxytocin could be taken to suggest a continuous pattern of secretion. However, frequent episodes of release would generate a profile not unlike that reported. Recordings of oxytocin levels in plasma and of intramammary pressure changes have been made in both the cow and the pig: in both species a 'spurt-like' release of oxytocin appears to occur (Cleverley \& Folley, 1970; Bruhn, Ellendorff, Forsling \& Poulain, 1981).

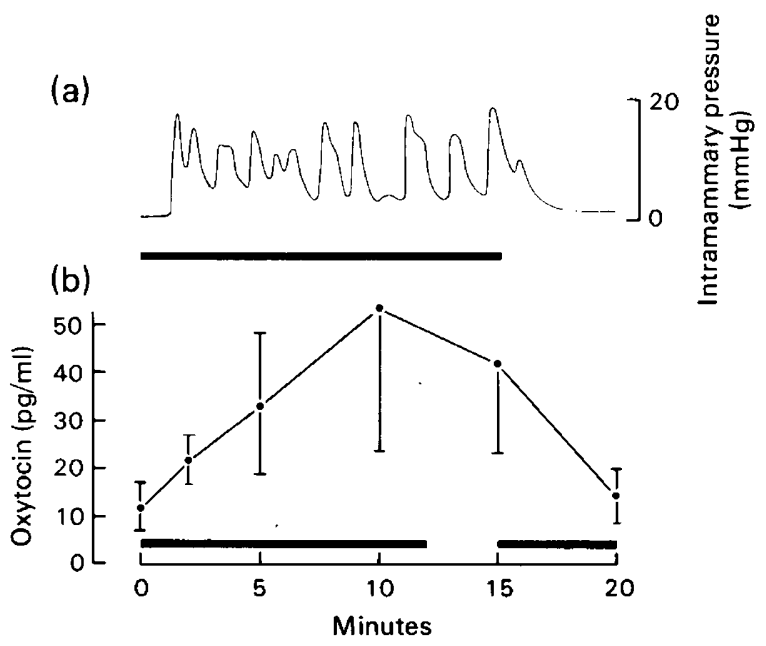

Text-fig. 4. Milk ejection and plasma levels of oxytocin in women during breast feeding. (a) A recording of intramammary pressure from a cannulated mammary duct during a period in which a baby was placed to feed on the contralateral breast for 15 min (event bar). Milk ejection commenced about $80 \mathrm{sec}$ into the nursing period; thereafter periodic rises in pressure were observed at intervals of 1-2 min. Adapted from Cobo et al. (1967). (b) Mean ( \pm s.e.m.) plasma levels of oxytocin determined for 12 women during breast feeding (event bar) at 3-5 days post partum. The babies were removed after $12 \mathrm{~min}$ and returned to the contralateral breast $3 \mathrm{~min}$ later. Data adapted from Dawood et al. (1981).

\section{Alternative strategies in milk ejection}

Domestic ruminants. In the goat, and to a lesser extent in other ruminants, most of the milk in the udder is stored in voluminous cisterns whence it can be withdrawn by suction applied to the nipple. Indeed, substantial milk yields have been obtained in the goat after denervation or transplantation of the udder (Linzell, 1963). In these species, therefore, a milk-ejection reflex is not essential for the feeding of the young, though it could facilitate the process (Text-fig. 1). This conclusion diverts our attention from the question of how milk is moved from the alveoli to the cisterns. The mechanism of secretion could itself generate sufficient pressure within the alveoli to force milk into the collecting ducts and cisterns. Alternatively, local contractions induced by the stretching of the myoepithelium could effectively pump milk into the cisterns.

Marsupials. Lactation and the associated question of milk ejection is far more complex in metatherian than eutherian mammals. The young are born in almost embryonic form and remain continuously attached to teats for some months in the macropodid species. Lactogenesis 
is confined to the mammary gland to which the neonate attaches, and the size of the gland increases throughout most of lactation to meet the increasing nutritional needs of the pouch young. In some species, for example the red kangaroo (Sharman \& Pilton, 1964) and the agile wallaby (Merchant, 1976), the problem is complicated by the fact that when the young leaves the pouch a new birth occurs and this initiates a second lactation in parallel to the previous one now feeding the juvenile at foot. How then is milk ejection organized during 'concurrent asynchronous lactation'? The mammary gland of the agile wallaby during early lactation is exquisitely sensitive to oxytocin and this sensitivity declines by an order of magnitude during the pouch life of young ( 200 days). The neonate is extremely small $(0.004 \%$ of the mother's weight at birth), and it is difficult to envisage such a minute offspring generating a sensory input sufficient to trigger a substantial release of oxytocin. On the other hand, a low or basal level of oxytocin could, due to the extreme sensitivity of myoepithelium, evoke recurring contractions. These, in the absence of a teat sphincter, would effectively pump milk into the attached neonate. Later in lactation the young is detached from the nipple for long periods and at this stage it would seem plausible that an eutherian style milk ejection reflex might operate (Lincoln \& Renfree 1981a, b). The fact that lactation continues for several months in the tammar wallaby, Macropus eugenii, after denervation of the lactating mammary gland (Renfree, 1979) suggests that milk ejection in early lactation is relatively independent of sensory stimuli from the nipple.

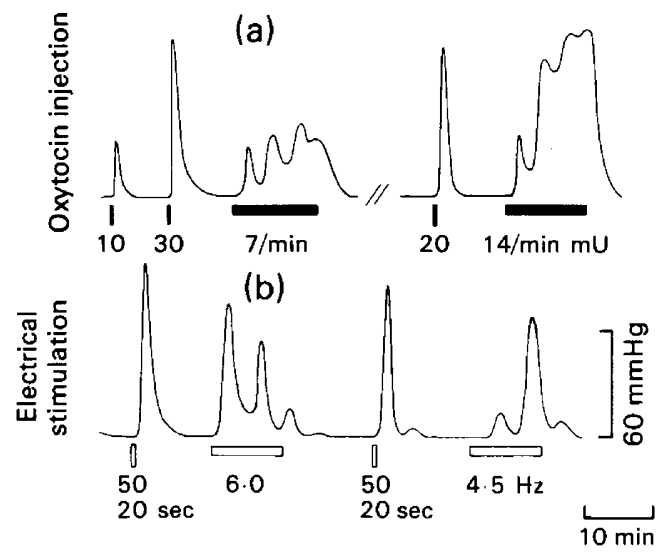

Text-fig. 5. Recordings of intramammary pressure from a cannulated galactophore of an agile wallaby, Macropus agilis, anaesthetized with pentobarbitone sodium. In (a) oxytocin was administered as a bolus injection or continuous infusion (event bar) into the external jugular vein. In (b) the responses produced by electrical stimulation of putative oxytocinergic neurones at high $(50 \mathrm{~Hz})$ and low frequencies $(4.5$ and $6.0 \mathrm{~Hz})$ are compared. Low frequency stimulation was continued for the duration of each event bar. Prolonged stimulation at $4.5 \mathrm{~Hz}$ caused milk ejection, whereas stimulation at $25 \mathrm{~Hz}$ was ineffective in the rat (see Text-fig. 2). Data adapted from Lincoln \& Renfree (1981a, b).

\section{The posterior pituitary and magnocellular nuclei}

The posterior pituitary is composed of pituicytes and the dilated axon terminals of neurones whose cell bodies are situated in the supraoptic and paraventricular nuclei of the hypothalamus. In the endoplasmic reticulum of these cells a peptide of about 20000 molecular weight is synthesized, and in the Golgi apparatus this peptide is packaged into membrane-bound granules (neurosecretory granules) for transport to the posterior pituitary. During axonal transport, which occurs at the fast rate of about $2 \mathrm{~mm} / \mathrm{h}$, the precursor peptide is cleaved to produce oxytocin (molecular weight 1007) and at least two other large peptide fragments. Thus, oxytocin represents but $5 \%$ of the precursor from which it was formed. The remainder of the peptide, 
including the neurophysin moiety, has no established function, but because it is contained within the neurosecretory granule it is released in parallel with oxytocin (Legros et al., 1974). Conversely, oxytocin (and vasopressin) may not be biologically active at other sites within the central nervous sytem where these peptides have been localized by immunohistochemistry (Sofroniew, 1980): at these sites other parts of the precursor could be active. Reviews on the ultrastructure (Morris, Nordmann \& Dyball, 1978) and biochemistry (Pickering, 1978) of the magnocellular systems should be consulted for further details on these topics. Attention in this review will be focussed on the electrophysiological activation of the magnocellular neurones during the release of oxytocin.

\section{Oxytocin release from the posterior pituitary}

The axon terminals of the posterior pituitary contain an enormous store of oxytocin when compared with the amount required to elicit milk ejection. The posterior lobe of the rat contains about $500 \mathrm{mU}$ oxytocin when less than $1 \mathrm{mU}$ is required for an individual milk ejection. This seems very insignificant, though in fact a rat may milk eject 100 times each day. From this one would calculate a daily turnover of $100 \mathrm{mU} /$ day or more during lactation, and that is considerably in excess of the turnover rate of $20 \mathrm{mU} /$ day estimated for a male rat in water balance (Jones \& Pickering, 1972). A similar and apparently excessive storage capacity is seen in studies of other species. The human pituitary contains 3000-9000 mU oxytocin (Lederis, 1961) whilst reflex milk ejection may involve a release of no more than 50-100 mU (Cobo et al., 1967). Much of the oxytocin is stored in non-terminal dilatations (or Herring bodies) and is not immediately available for release. However, the size of the so-called readily releasable pool, which is presumably a measure of those granules situated close to the terminal membrane, is still large when compared with the physiological requirements outlined above. The importance of this enormous storage capacity is not understood, but it is of some practical importance. There is of course no pressing requirement to link peptide biosynthesis to release, other than over a period of many hours or even days. Secondly, there is little experimental value in attempting to measure hormone depletion as an index of biological function.

Nerve action potentials invading the terminals of the posterior pituitary cause an influx of $\mathrm{Ca}^{2+}$ ions, and as a consequence of this increase in intracellular calcium neurosecretory granules fuse with the terminal membrane and release their contents by exocytosis. Granule membrane is then taken back into the terminal (Theodosis, Dreifuss, Harris \& Orci, 1976), free calcium is sequestered, probably into microvesicles (Shaw \& Morris, 1980), and the membrane potential is restored through an energy-dependent sodium-potassium interchange. Through this process of stimulus-secretion coupling (Douglas \& Poisner, 1964) a relationship is established which suggests that hormone release is a direct function of the number of action potentials entering the posterior pituitary from their origin in the magnocellular nuclei of the hypothalamus. In fact, this substantially under estimates the ability of the system. Action potentials entering the posterior pituitary along a given axon at a rate of $50 / \mathrm{sec}$ release perhaps 100 times as much oxytocin per potential when compared with those arriving at 1-5/sec (Lincoln, 1974a). One explanation for this phenomenon of frequency facilitation is that short inter-spike intervals lead to an accumulation of calcium ions in the terminal; alternatively it could relate to the progressive movement of granules towards the terminal membrane. Evidence for frequency facilitation has arisen largely from studies involving electrical stimulation of the posterior pituitary. Both in vivo (Harris, Manabe \& Ruf, 1969) and in vitro (Dreifuss, Kalnins, Kelly \& Ruf, 1971) the optimal frequency of electrical stimulation is $30-50 \mathrm{~Hz}$ using square wave pulses of about $1 \mathrm{msec}$. The rabbit (Harris et al., 1969), pig (Bruhn et al., 1981) and guinea-pig (A. Thomson \& D. W. Lincoln, unpublished observations) have also been studied to determine the optimal parameters of electrical stimulation of the posterior pituitary; all suggest that a high-frequency volley of pulses generates the most effective mammary contraction. 


\section{Electrophysiological correlates of oxytocin release}

The rat is the only species in which electrophysiological recordings have been made of oxytocinergic neurones during reflex milk ejection, because it is the only readily available species of a convenient size that displays a 'normal' pattern of milk ejection when deeply anaesthetized. Thus it has been possible to record simultaneously intramammary pressure and the firing of antidromically-identified magnocellular neurones, and then to monitor changes in activity elicited by the sucking of the young. About $50 \%$ of neurones in both the supraoptic and paraventricular nuclei display an explosive acceleration in activity for 2-4 sec, at about 10-12 sec before the rise in intramammary pressure at milk ejection (Wakerley \& Lincoln, 1973; Lincoln \& Wakerley, 1974, 1975). Their peak rate of firing is some $20-80$ action potentials/sec compared with a background discharge of $0-5$ spikes/sec (Text-fig. 6). This period of accelerated activity is remarkably consistent in both duration and frequency of discharge. Most important, the interval between the neurosecretory burst and the rise in intramammary pressure is constant. Thus we are observing a synchronized acceleration in the firing of all ' 9000 ' oxytocinergic neurones in the supraoptic and paraventricular nuclei. When recordings were made of putative oxytocinergic neurones in the unanaesthetized rat during nursing using chronically implanted microwire electrodes (Summerlee \& Lincoln, 1981), periods of accelerated activity virtually indistinguishable from those monitored under anaesthesia were observed some 10-12 sec before milk ejection (Text-fig. 7). This latency to milk ejection corresponds closely to that observed after electrical stimulation of the posterior pituitary, and is some $2 \mathrm{sec}$ longer than that observed after an intravenous injection of exogenous oxytocin.

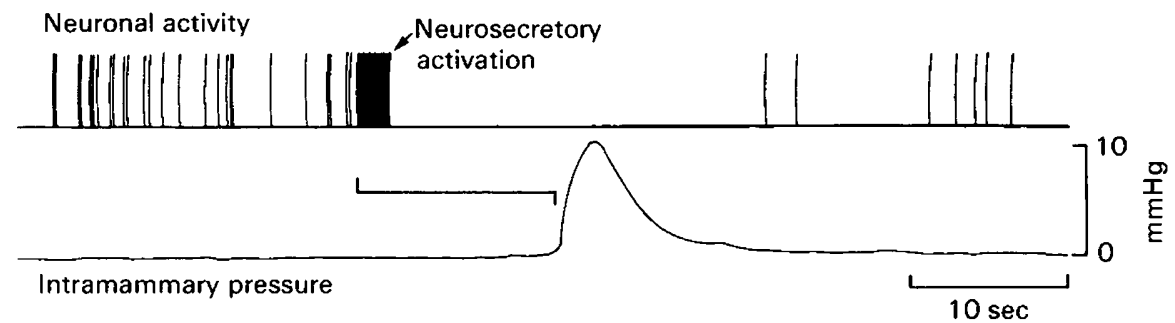

Text-fig. 6. A recording of the pattern of activity exhibited by a single antidromically-identified oxytocinergic neurone during suckling in an anaesthetized lactating rat. Each deflection on the upper trace corresponds to a single action potential. A dramatic increase in spike activity was observed about $12 \mathrm{sec}$ before milk ejection, as indicated by the rise in intramammary pressure (lower trace).

There are two very important features of these electrophysiological recordings. The peak rate of firing of 20-80 action potentials/sec covers the range in which frequency facilitation of oxytocin release is observed in studies with electrical stimulation. Secondly, the period of accelerated activity appears to occur synchronously throughout the magnocellular complex. Thus the 9000 or so oxytocin cells would appear to transmit to the posterior pituitary about 540000 action potentials in 2-4 sec for the release of about $2 \mathrm{ng}$ oxytocin. By division, therefore, one action potential releases $3 \mathrm{fg}$ oxytocin or the contents of 40 neurosecretory granules (Lincoln, 1974a; Cross et al., 1975). The response is elegant in two other respects. The background discharge of $0-5$ spikes/sec does not contain interspike intervals sufficiently short to evoke facilitation of oxytocin release. One would therefore predict little oxytocin release in response to the background firing of the neurones. Secondly, each burst of activity is followed by a $10-30 \mathrm{sec}$ hiatus in background discharge (after-inhibition). Many neurones would have generated 30-80 action potentials in this time, i.e. a number similar to that contained in the explosive burst that evokes milk ejection. 
(a) EEG activity
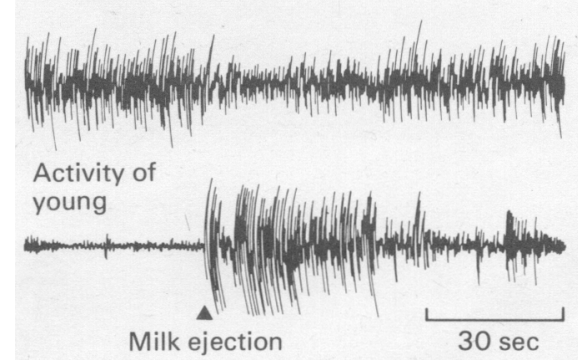

(b) Neuronal activity

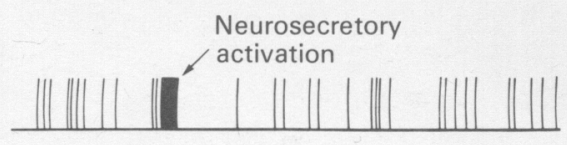

Activity of

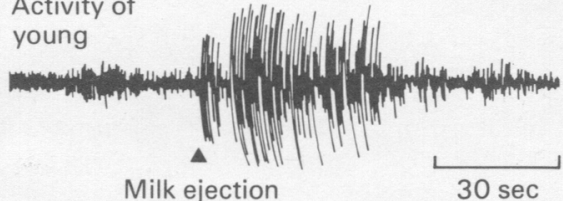

Text-fig. 7. Electrophysiological recordings from unanaesthetized rats during nursing. The activity of the young (and mother) was recorded by radar; this was used to time the occurrence of milk ejection in the absence of recordings of intramammary pressure (see Text-fig. 3). (a) A recording of the electroencephalogram (EEG) from the frontal cortex. A sleep-like EEG pattern of large amplitude waves was present in the period immediately before milk ejection. Coincident with milk ejection and the vigorous increase in the activity of the young the EEG changed to a pattern of low-amplitude fast waves (=wakefulness). (b) A recording of the pattern of spike activity exhibited by a putative oxytocinergic neurone obtained via a chronically implanted microwire electrode. Each deflection corresponds to a single potential. An explosive increase in firing was observed 10-12 sec before milk ejection, as in anaesthetized rats. This recording was kindly provided by Dr A. J. S. Summerlee.

Until recently there was every reason to think that explosive bursts of electrical activity in the magnocellular nuclei might underlie the release of oxytocin in other species, and indeed this may be so when oxytocin is released in a pulsatile pattern. However, electrical stimulation of the pituitary stalk of the agile wallaby has shown that milk ejection can be evoked by stimulation at frequencies below $5 \mathrm{~Hz}$ (Text-fig. 5) (Lincoln \& Renfree, 1981a). Frequencies of $5 \mathrm{~Hz}$ are found in the spontaneous discharge of many magnocellular neurones in the rat, and these have been largely dismissed as representing background noise. It now appears plausible that, in the wallaby, and perhaps therefore in other species, minor changes in electrical activity could create a low but sustained release of oxytocin of physiological importance.

\section{Inhibition of oxytocin release within the posterior pituitary}

The blood-brain barrier represents a restriction to the free movement of regulatory peptides between the peripheral circulation and the brain, and vice versa. The magnocellular neurones bridge this barrier: their cell bodies are within the brain whilst their terminals in the posterior pituitary are outside and subject to peripheral influences.

The posterior pituitary contains high affinity opiate receptors (Simantov \& Snyder, 1977). Secondly, the neurointermediate lobe of the pituitary produces a large amount of $\beta$-endorphin, and there is every reason to think that $\beta$-endorphin, released during stress (Guillemin et al., 1977), could reach the posterior pituitary. Our involvement in this field, however, began with the discovery that naloxone, an opiate antagonist, would facilitate the electrically induced release of oxytocin from the posterior pituitary in rats that were otherwise refractory to stimulation. This suggested an inhibition of release at the level of the terminal by an endogenous opioid. Subsequently, morphine placed in the cerebral ventricles was observed to inhibit stimulus-evoked release of oxytocin from the posterior pituitary (Clarke, Wood, Merrick \& Lincoln, 1979). As expected, morphine blocked the suckling-induced release of oxytocin but to our surprise explosive bursts of electrical activity were still displayed by the hypothalamic magnocellular neurones. Opiates therefore appear to block stimulus-secretion coupling by dissociating electrical activity from peptide release at the terminal. More recent studies on the isolated posterior pituitary have shown that the release of both oxytocin and vasopressin is substantially 
reduced when electrical stimulation has been applied to the cut pituitary stalk after morphine, $\beta$-endorphin and long-acting enkephalin analogues have been added to the incubation medium, and the inhibition is naloxone reversible (Iversen, Iversen \& Bloom, 1980; G. Patrick \& G. Clarke, personal communication). Such an effect on the posterior pituitary is analogous to the presynaptic inhibitory action of opiates in other areas of the central nervous system (Jessell \& Iversen, 1977).

Whilst $\beta$-endorphin released from the neurointermediate lobe could act to inhibit oxytocin release during stress, a new possibility has arisen with the discovery of enkephalin-containing neurones innervating the posterior pituitary (Rossier et al., 1979). Furthermore, Martin \& Voigt (1981) have provided immunohistochemical evidence to suggest a possible co-existence of met-enkephalin with oxytocin and leu-enkephalin with vasopressin within magnocellular neurones. The levels of enkephalin (Rossier et al., 1979) in the posterior pituitary are very small (1920 pg met-enkephalin/lobe and $503 \mathrm{pg}$ leu-enkephalin/lobe) compared with the content of oxytocin $(1 \mu \mathrm{g} / \mathrm{lobe})$. However, such a small amount of enkephalin may not be insignificant if it acts locally onto the terminal from which it has been released. This is short-loop feedback in the extreme, and by inhibiting further hormone release it could abruptly terminate each period of secretion.

\section{Afferent signals for oxytocin release}

The sensory input to the oxytocinergic neurone is probably the least understood aspect of the milk ejection reflex. Proprioceptive stimuli applied to the nipple clearly provide the main afferent signal, though in many species the sight or sound of the young or other features of the nursing/milking routine may trigger milk ejection.

\section{Sensory receptors in the nipple}

The nipple and the skin covering the mammary gland is richly innervated with somatosensory nerve endings that respond to touch and pressure (Findlay, 1966; Cross \& Findlay, 1969; Montagna \& Macpherson, 1974). A dramatic increase in tactile sensitivity of the human breast has been recorded within 1-2 days of delivery, with smaller increases at ovulation and menstruation (Robinson \& Short, 1977). These changes in proprioceptive sensibility appear to be caused by falling hormone concentrations rather than increases in gland volume. Similarly, Tyson, Friesen \& Anderson (1972) found that stimulation of the woman caused a release of prolactin immediately after but not during a period of oestrogen treatment. Such changes in sensory perception could be mediated at the receptor or at some point within the central nervous system.

Most of the pressure receptors in the nipple of the rabbit are of a rapidly adapting type. In recordings of single nerve fibres of an abdominal segmental nerve in a lactating rabbit, Findlay (1966) observed dynamic changes in electrical activity that paralleled closely the individual sucking motions of the young. The innervation of the mammary parenchyma is sparse, though Findlay (1966) observed some nerve fibres that responded to pressure and to traction on the interlobular septa after removal of the skin. This weak innervation of the parenchyma probably provides information on the state of mammary engorgement and of the pressure changes at milk ejection. It is, however, the proprioceptive innervation of the nipple that is important for reflex milk ejection (Sala, Luther, Arballo \& Cordero-Funes, 1974). In the rabbit, a species which does not milk eject in response to the sight, sound or smell of the young, reflex milk ejection does not occur after the nipples have been locally anaesthetized with lignocaine (Findlay, 1968).

Findlay's (1966) recordings from mammary nerves demonstrated a very direct relationship between the sucking motions of the young and the information that passes into the spinal cord. 
Therefore, in the absence of such electrical recordings, it is possible to glean some insight into the sensory information being transmitted to the brain through a detailed examination of the sucking activities of the young. Wakerley \& Drewett (1975) observed individual rat young to suck in bursts (2-10 sucks in $1-5 \mathrm{sec}$ ) at irregular intervals (about $1-3$ times $/ \mathrm{min}$ ) (Text-fig. 8 ). The suction applied during each burst generated a negative pressure of $50-100 \mathrm{mmHg}$ lasting about $10 \mathrm{sec}$. This suction is considerably in excess of the $8-10 \mathrm{mmHg}$ pressure recorded from the mammary galactophore at milk ejection. No increase or synchronization of sucking activity was observed in the period 10-12 sec before milk ejection, i.e. coincident with the explosive acceleration in the firing of the oxytocinergic neurones. There is, however, ample evidence to indicate that milk ejection in the rat is a function of the sucking stimulus. Milk ejection in the anaesthetized rat does not occur when the number of young attached to the nipples is reduced to 6 or less. On the other hand, when a rat has been suckled for some time by 6 young, a milk ejection involving a release of endogenous oxytocin can be elicited within seconds by the application of a 7 th young rat, the dilatation of a cannulated galactophore with $0.2 \mathrm{ml}$ saline or the injection of oxytocin (i.v.) (Lincoln \& Wakerley, 1975)

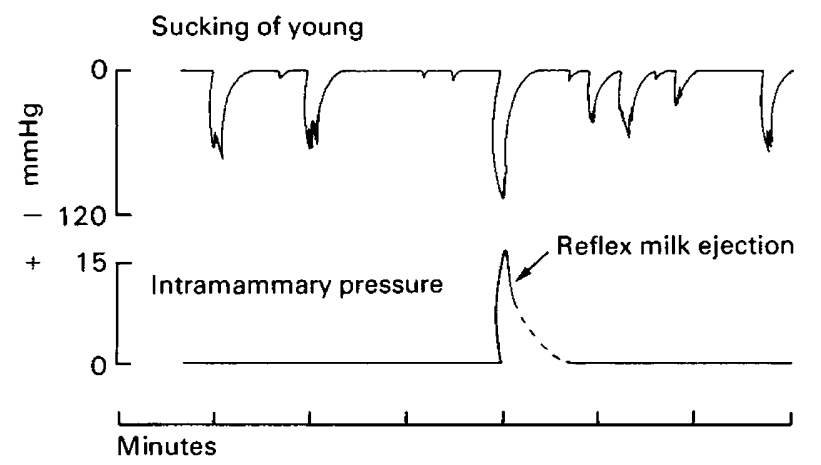

Text-fig. 8. A simultaneous recording of the sucking of a single rat young and intramammary pressure. The measurement of sucking activity was obtained by a cannulation of a nipple towards the sucking young: intramammary pressure was recorded by the cannulation of another nipple in the reverse direction. Bursts of sucking activity were observed at irregular intervals. Some increase in activity was observed at milk ejection. This was probably due to an interaction between the young because the cannulation procedure would in all probability have prevented the young perceiving milk ejection through the nipple to which it was attached. (Adapted from Wakerley \& Drewett, 1975.)

\section{Central mechanisms in the regulation of oxytocin release}

Pulse frequency. The interval between one milk ejection and the next is remarkably regular when a rat is suckled under anaesthesia (Lincoln et al., 1973, 1980) (Text-fig. 2). The mean interval is usually in the range of $2-10 \mathrm{~min}$, but differs slightly between animals and according to the anaesthetic used. The interval cannot be reset by the introduction of additional milk ejections evoked by the injection or infusion of exogenous oxytocin (Lincoln, 1974b) or the release of endogenous oxytocin by electrical stimulation of the posterior pituitary (Wakerley \& Deverson, 1975). For some minutes after milk ejection the mechanism governing oxytocin release appears to be refractory to further stimulation. Otherwise, the intense sucking activity observed at milk ejection would trigger a further release of oxytocin, and further milk ejections would recur at intervals of $10-20 \mathrm{sec}$. Just occasionally a situation akin to this is observed: a milk ejection evoked by exogenous oxytocin is sometimes followed after about $20 \mathrm{sec}$ by an endogenouslymediated milk ejection. In normal circumstances the interval between milk ejections would appear to be independent of oxytocin feedback and of events related to milk ejection at the level of the mammary gland. 
There are two experimental manipulations that appear to bypass the mechanism determining pulse frequency. Electrical stimulation applied to a single mammary nerve $(15 \mathrm{~Hz}$ for $5-15 \mathrm{sec})$ of a lactating rat under urethane anaesthesia evokes a milk ejection equivalent to that mimicked by $50-400 \mu \mathrm{U}$ oxytocin (Mena, Pacheco, Aguayo, Clapp \& Grosvenor, 1978). This is not a large release of oxytocin when compared with the $500-1000 \mu \mathrm{U}$ released at reflex milk ejection, but it occurs in response to stimulation of a single mammary nerve. In these same anaesthetic circumstances it would have taken the sucking of 7 or more young to elicit milk ejection. In addition there appeared to be no refractory period following stimulation and repeatable responses were obtained by stimulation of the mammary nerve at intervals of $40 \mathrm{sec}$.

Sleep and anaesthesia. Oxytocin release from the posterior pituitary of the rat during the nursing of her young only occurs when the electroencephalogram (EEG) recorded from the cerebral cortex is synchronized and consists of large amplitude slow waves akin to those associated with sleep (Text-fig. 7) (Lincoln, 1973; Voloschin \& Tramezzani, 1979; Lincoln et al., 1980). Therefore any stimulus that causes arousal or wakefulness blocks reflex milk ejection. Conversely, the association between sleep and milk ejection may account for why reflex milk ejection in the rat is observed during anaesthesia. Reflex milk ejection in the rat has been observed under many anaesthetics (urethane, avertin, ethyl alcohol, pentobarbitone sodium, diazepam, xylazine and combinations thereof) (Text-fig. 2); in all cases milk ejection is confined to periods in which the EEG is synchronized. Ketamine and neurolept anaesthetic combinations are not satisfactory. Ketamine produces a depressed EEG pattern with occasional spindles: an index at least of very abnormal brain activity. The neurolept combinations are unsatisfactory because they contain an opiate in the form of fentanyl or etorphine for example, and that inhibits oxytocin release from the pituitary as previously discussed. EEG patterns under anaesthesia are still to some extent a function of sensory inputs. The EEG of the rat under urethane anaesthesia alternates 'spontaneously' between large-amplitude slow waves and low-amplitude fast waves (desynchronization/arousal) (Lincoln, 1969). Indeed, relatively mild sensory stimuli such as stroking of the skin will evoke EEG arousal and inhibit reflex milk ejection. However, the sucking of the nipples by the young is unusual in this respect because the application of the young induces an hour or more of continuous slow-wave EEG activity, i.e. the stimulus is soporific (Lincoln et al., 1980).

In no species other than the rat has an association between sleep and milk ejection been observed. With many species the period of nursing is one of danger to both mother and young, and it does not require EEG recordings to determine that many animals remain very alert throughout the nursing period. Perhaps wakefulness is even a pre-requisite for milk ejection (Poulain, Rodriguez \& Ellendorff, 1981; H. Neve, A. C. Paisley \& A. J. S. Summerlee, unpublished).

Central inhibition. Reflex milk ejection is inhibited by emotional factors, and there is a considerable body of evidence which indicates that this inhibition occurs within the central nervous system (Cross, 1955; Aulsebrook \& Holland, 1969). A proportion of rats when anaesthetized do not milk eject when suckled by a large litter, but do so after the administration of centrally active $\beta$-adrenoceptor blocking drugs such as propranolol and oxprenolol at doses as low as $30 \mu \mathrm{g} / \mathrm{kg}$ (Tribollet, Clarke, Dreifuss \& Lincoln, 1978). Practolol, an antagonist with limited access to the brain, was ineffective at $1.5 \mathrm{mg} / \mathrm{kg}$. Central inhibition might therefore involve a release of noradrenaline onto $\beta$-adrenoceptors. Noradrenergic terminals have been observed in the hypothalamic magnocellular nuclei and noradrenaline applied iontophoretically to antidromically identified neurones in these nuclei has been shown to inhibit cell firing via a $\beta$-receptor mechanism (Barker, Crayton \& Nicoll, 1971). However, propranolol has no effect on the spontaneous firing of oxytocinergic neurones even when, in refractory animals, it had facilitated milk ejection (Tribollet et al., 1978). Propranolol would thus appear to act at some site other than the magnocellular nuclei. 


\section{Afferent pathways in reflex milk ejection}

The central pathways involved in the transmission of the afferent stimuli for the release of oxytocin have been extensively reviewed (Cross \& Dyball, 1974; Tindal, 1978). There is still considerable controversy as to the pathways involved, this is due to the pathways being diffuse and to the differences between species. There are, however, technical reasons that make the tracing of these pathways quite difficult. Activation of nocioceptive pathways will in all probability inhibit milk ejection, either centrally or through the release of opioid peptides and/or adrenaline. Nocioceptive pathways run in the antero-lateral parts of the spinal cord together with fibres transmitting proprioceptive stimuli from the nipple. It is difficult, if not impossible, to stimulate one without the other. Furthermore, electrical stimulation of many parts of the brain stem of the rat will create EEG arousal, again inhibiting what one is attempting to evoke. Conversely, studies with ablation techniques are confounded by the diffuse nature of the pathways. Voloschin \& Dottaviano (1976) had almost to transect completely the midbrain of the rat in an attempt to abolish suckling-induced milk ejection.

Whilst our anatomical knowledge of the milk ejection pathways is far from complete, a considerable amount of information has accumulated on the neurotransmitters mediating the suckling-induced response. As already discussed, the anaesthetized rat when sucked by a large litter of hungry young will milk eject at regular intervals. This pattern of activity closely resembles that expressed by the conscious rat, but anaesthesia allows the number of young attached to the nipples to be controlled, facilitates the measurement of intramammary pressure, promotes synchronization of the EEG, and permits neurotransmitter antagonists, agonists and synthesis inhibitors to be administered acutely either intravenously or into the cerebral ventricles. No transmitter antagonist or agonist has been found that increases the frequency of milk ejection evoked by the young. Antagonists to acetylcholine, noradrenaline and dopamine cause an inhibition of the suckling-induced reflex that is dose related, while antagonists to histamine, 5-hydroxytryptamine and gamma-aminobutyric acid are without effect.

Acetylcholine. Reflex milk ejection in the anaesthetized rat is abolished by cholinoceptor antagonists of the nicotinic type such as mecamylamine and hexamethonium (Clarke, Fall, Lincoln \& Merrick, 1978). Antagonists of the muscarinic type cause no inhibition at very high doses (e.g. atropine, $200 \mathrm{mg} / \mathrm{kg}$ i.v.). This contradicts many of the earlier observations in which atropine was shown to be inhibitory, but in none of the earlier studies were the experiments controlled to take into account the many non-specific mechanisms by which milk ejection may be inhibited (e.g. EEG arousal). Conversely, the injection of cholinomimetics (acetylcholine, 20-100 $\mu \mathrm{g}$; bethanechol, $0.2-4.0 \mu \mathrm{g}$; carbachol, $0.01-0.2 \mu \mathrm{g}$ ) into the cerebral ventricles evoked a large and sustained release of oxytocin (Text-fig. 2) (Clarke et al., 1978). This release of oxytocin was abolished by atropine at $0.1-1.0 \mathrm{mg} / \mathrm{kg}$, i.v., whereas nicotinic antagonists had no effect. Such an observation suggests the existence within the central nervous system of a second oxytocin-releasing pathway characterized by cholinergic-muscarinic transmission. This pathway might relate to the induction of oxytocin release by exteroceptive cues perceived and analysed by higher nervous centres, e.g. the sight of the young, because most cholinergic synapses in the cerebral cortex are of a muscarinic type (Krnjevic \& Phillis, 1963).

Noradrenaline. A case has already been made for the involvement of noradrenaline in the central inhibition of oxytocin release by $\beta$-adrenoceptors, and as previously mentioned $\beta$-adrenoceptor antagonists do not influence the ongoing pattern of reflex milk ejection. Alpha-adrenoceptor antagonists, by contrast, cause a dose-related inhibition of suckling-induced milk ejection. Phentolamine at $1 \mathrm{mg} / \mathrm{kg}$ increased the milk ejection interval 6 -fold and at 2 $\mathrm{mg} / \mathrm{kg}$ increased the interval 13-fold (Tribollet et al., 1978). There is considerable confusion regarding the effects of centrally administered noradrenaline on the release of oxytocin. The result is clearly going to depend on the predominant effect: inhibition via $\beta$-receptors and excitation by $\alpha$-receptors. 
Dopamine. Dopamine antagonists block reflex milk ejection in the rat, and their rank order of potency corresponds closely with comparisons made using dopamine receptor binding (Clarke, Lincoln \& Merrick, 1979). Likewise, milk ejection was inhibited quite rapidly by inhibitors of catecholamine synthesis, e.g. diethyldithiocarbamate and $\alpha$-methylparatyrosine. The opposite procedure produced the expected result. Dopamine $(40 \mu \mathrm{g})$ and bromocriptine $(10$ $\mu \mathrm{g})$ placed in the lateral ventricles of the rat brain caused a significant release of oxytocin, though the result was not as repeatable as that involving carbachol injection. A more recent study has provided supportive evidence in that no change in the milk ejection reflex of the rat was observed after the administration of bromocriptine at $4 \mathrm{mg} / \mathrm{kg}$ s.c. (Russell, Harrison \& McNeilly, 1981). In studies of electrical activity, dopamine produced an intermittent and burst-like acceleration in the firing of putative oxytocinergic neurones. This contrasts with the sustained elevation (15 min duration) in action potential activity evoked by intraventricular injections of carbachol. It therefore seems plausible that dopamine may be involved in the mechanism underlying pulsatile release.

\section{Milk ejection in the rat: 10 principles of organization}

(1) The mammary gland responds most efficiently to bolus injections of oxytocin $(\sim 1 \mathrm{mU})$ delivered at intervals of $3 \mathrm{~min}$ or greater.

(2) Pulses of $0.5-1.0 \mathrm{mU}$ oxytocin are released from the posterior pituitary at regular intervals of 2-10 min during nursing, although the young remain attached to the nipples throughout. A lactating rat suckles for about $18 \mathrm{~h}$ each day and milk ejects about 100 times.

(3) The posterior pituitary contains $500 \mathrm{mU}$ oxytocin: 1000 times the amount required to elicit an individual milk ejection.

(4) Each pulse of oxytocin released from the pituitary is created by an explosive 2-4 sec acceleration in the firing of the oxytocin-producing neurones. This dramatic increase in activity occurs synchronously throughout the hypothalamic magnocellular nuclei and the high frequencies of activity (20-80 action potentials/sec) enhance by a factor of 100 or more the amount of hormone released by each action potential.

(5) The interval between one milk ejection and the next is determined by central factors: it is not governed by the number of young attached to the nipples, and cannot be reset by the experimental introduction of additional milk ejections.

(6) The release of oxytocin is sleep related, and release is inhibited by any stimulus that produces arousal/wakefulness. Most anaesthetics do not prevent sucking-induced milk ejection providing they induce a 'sleep-like' EEG.

(7) The reflex pathway mediating oxytocin release contains synaptic mechanisms activated by noradrenaline, acetylcholine and dopamine. 5-Hydroxytryptamine and gamma-aminobutyric acid do not appear to be involved.

(8) Proprioceptive inputs from the nipple provide the main stimulus for oxytocin release, but there is no increase in sucking activity coincident with the explosive acceleration in the firing of the oxytocin neurones.

(9) The young display a vigorous increase in sucking activity immediately following the rise in intramammary pressure; this is a response to milk ejection and not a trigger for oxytocin release.

(10) Reflex milk ejection is inhibited by adrenaline at the level of the mammary gland, by opioid peptides influencing secretion from the terminals of oxytocin-producing neurones in the posterior pituitary, and by noradrenaline acting on $\beta$-adrenoceptors within the central nervous system.

The authors acknowledge the financial support of the Medical Research Council. 


\section{References}

Alexandrova, M. \& Soloff, M.S. (1980) Oxytocin receptors and parturition. III. Increases in estrogen receptor and oxytocin receptor concentrations in the rat myometrium during prostaglandin $\mathrm{F}_{2}$ a-induced abortion. Endocrinology 106, 739-743.

Aulsebrook, L.H. \& Holland, R.C. (1969) Central inhibition of oxytocin release. Am. J. Physiol. 216, $830-842$.

Barker, J.L., Crayton, J.W. \& Nicoll, R.A. (1971) Noradrenaline and acetylcholine responses of supraoptic neurosecretory cells. J. Physiol., Lond. 218, 19-32.

Berde, B. \& Boissonnas, R.A. (1968) Basic pharmacological properties of synthetic analogues and homologues of the neurohypophysial hormones. Hand. Exp. Pharm. 23, 802-870.

Bisset, G.W., Clark, B.J. \& Lewis, G.P. (1967) The mechanism of the inhibitory action of adrenaline on the mammary gland. $\mathrm{Br} . J$. Pharmacol. Chemother. 31, 550-559.

Bisset, G.W., Clark, B.J. \& Haldar, J. (1970) Blood levels of oxytocin and vasopressin during suckling in the rabbit and the problem of their independent release. J. Physiol., Lond. 206, 711-722.

Bruhn, T., Ellendorf, F., Forsling, M.L. \& Poulain, D.A. (1981) Neurohypophysial hormone release during natural and induced milk ejection in the sow. $J$. Physiol., Lond. (in press).

Clarke, G., Fall, C.H.D., Lincoln, D.W. \& Merrick, L.P. (1978) Effects of cholinoceptor antagonists on the suckling-induced and the experimentally evoked release of oxytocin. Br. J. Pharmac. 63, 519-527.

Clarke, G., Lincoln, D.W. \& Merrick, L.P. (1979) Dopaminergic control of oxytocin release in lactating rats. J. Endocr. 83, 409-420.

Clarke, G., Wood, P., Merrick, L. \& Lincoln, D.W. (1979) Opiate inhibition of peptide release from the neurohumoral terminals of hypothalamic neurones. Nature, Lond. 282, 746-748.

Cleverley, J.D. \& Folley, S.J. (1970) Blood oxytocin during machine milking in cows. J. Endocr. 46, 347-361.

Cobo, E., De Bernal, M.M., Gaitan, E. \& Quintero, C.A. (1967) Neurophypophyseal hormone release in the human. II. Experimental study during lactation. $A m$. J. Obstet. Gynec. 97, 519-529.

Cross, B.A. (1955) Neurohormonal mechanisms in emotional inhibition of milk ejection. J. Endocr. 12, 29-37.

Cross, B.A. \& Dyball, R.E.J. (1974) Central pathways for neurohypophysial hormone release. In Handbook of Physiology, Section 7, Vol. 4, The Pituitary Gland, Part 1, pp. 269-285. Eds E. Knobil \& W. H. Sawyer. American Physiological Society, Washington, D.C.

Cross, B.A. \& Findlay, A.L.R. (1969) Comparative and sensory aspects of milk ejection. In Lactogenesis: the Initiation of Milk Secretion at Parturition, pp. 245-252. Eds M. Reynold \& S. J. Folley. University of Pennsylvania Press, Philadelphia.

Cross, B.A., Dyer, R.G., Dyball, R.E.J., Jones, C.A., Lincoln, D.W., Morris, J.F. \& Pickering, B.T. (1975) Endocrine neurones. Recent Prog. Horm. Res. 31, 243-292.
Dawood, M.Y., Khan-Dawood, F.S., Wahi, R.S. \& Fuchs, F. (1981) Oxytocin release and plasma anterior pituitary and gonadal hormones in women during lactation. J. clin. Endocr. Metab. 52, 678683.

Douglas, W.W. \& Poisner, A.M. (1964) Stimulussecretion coupling in a neurosecretory organ and the role of calcium in the release of vasopressin from the neurohypophysis. J. Physiol., Lond. 172, 1-18.

Dreifuss, J.J., Kalnins, I., Kelly, J.S. \& Ruf, K.B. (1971) Action potentials and release of neurohypophysial hormones in vitro. J. Physiol., Lond. 215, 805-817.

Findlay, A.L.R. (1966) Sensory discharges in lactating mammary glands. Nature, Lond. 211, 1183-1184.

Findlay, A.L.R. (1968) The effect of teat anaesthesia on the milk-ejection reflex in the rabbit. J. Endocr. 40, 127-128.

Guillemin, R., Vargo, T., Rossier, J., Minick, S., Ling, N., Rivier, C., Vale, W. \& Bloom, F.E. (1977) $\beta$ endorphin and ACTH are secreted concomitantly by the pituitary gland. Science, N.Y. 197, 1367-1369.

Harris, G.W., Manabe, Y. \& Ruf, K.B. (1969) A study of the parameters of electrical stimulation of myelinated fibres in the pituitary stalk. $J$. Physiol., Lond. 203, $67-81$.

Iversen, L.L., Iversen, S.D. \& Bloom, F.E. (1980) Opiate receptors influence vasopressin release from nerve terminals in rat neurohypophysis. Nature, Lond. 284, $350-351$.

Jessell, T.M. \& Iversen, L.L. (1977) Opiate anaigesics inhibit substance $\mathbf{P}$ release from rat trigeminal nucleus. Nature, Lond. 268, 549-551.

Jones, C.W. \& Pickering, B.T. (1972) Intra-axonal transport and turnover of neurohypophysial hormones in the rat. J. Physiol, Lond. 227, 553-564.

Krnjevic, K. \& Phillis, J.W. (1963) Pharmacological properties of ACh-sensitive cells in the cerebral cortex. J. Physiol., Lond. 166, 328-350.

Lederis, K. (1961) Vasopressin and oxytocin in the mammalian hypothalamus. Gen. Comp. Endocr. 1, $80-89$.

Legros, J.J., Reynaert, R. \& Peeters, G. (1974) Specific release of bovine neurophysin I during milking and suckling in the cow. J. Endocr. 60, 327-332.

Lincoln, D.W. (1969) Correlation of unit activity in the hypothalamus with the EEG patterns associated with the sleep cycle. Expl Neurol. 24, 1-18.

Lincoln, D.W. (1973) Milk ejection during alcohol anaesthesia in the rat. Nature, Lond. 243, 227-229.

Lincoln, D.W. (1974a) Dynamics of oxytocin secretion. In Neurosecretion-the Final Neuroendocrine Pathway, pp. 192-194. Eds F. Knowles \& L. Vollrath. Springer-Verlag, Heidelberg.

Lincoln, D.W. (1974b) Does a mechanism of negative feedback determine the intermittent release of oxytocin during suckling? J. Endocr. 60, 193-194.

Lincoln, D.W. \& Renfree, M.B. (1981a) Milk ejection in a marsupial, Macropus agilis. Nature, Lond. 289, 504-506.

Lincoln, D.W. \& Renfree, M.B. (1981b) Mammary gland growth and milk ejection in the agile wallaby, Macropus agilis, displaying concurrent asynchronous lactation. J. Reprod. Fert. 63, 193-203. 
Lincoln, D.W. \& Wakerley, J.B. (1974) Electrophysiological evidence for the activation of supraoptic neurosecretory cells during the release of oxytocin. $J$. Physiol., Lond. 242, 533-554.

Lincoln, D.W. \& Wakerley, J.B. (1975) Factors governing the periodic activation of supraoptic and paraventricular neurosecretory cells during suckling in the rat. $J$. Physiol., Lond. 250, 443-461.

Lincoln, D.W., Hill, A. \& Wakerley, J.B. (1973) The milk ejection reflex of the rat: an intermittent function not abolished by surgical levels of anaesthesia. $J$. Endocr. 57, 459-476.

Lincoln, D.W., Hentzen, K., Hin, T., van der Schoot, P., Clarke, G. \& Summerlee, A.J.S. (1980) Sleep: a prerequisite for refiex milk ejection in the rat. Expl Brain Res. 38, 151-162.

Linzell, J.L. (1963) Some effects of denervating and transplanting mammary glands. $Q . J l$ exp. physiol. 48, 34-60.

Martin, R. \& Voigt, K.M. (1981) Enkephalins co-exist with oxytocin and vasopressin in nerve terminals of rat neurohypophysis. Nature, Lond. 289, 502-504.

McCracken, J.A. (1980) Hormone receptor control of prostaglandin $\mathrm{F}_{2} \alpha$ secretion by the ovine uterus. $A d v$. Prost. Thromb. Res. 8, 1329-1344.

Mena, F., Pacheco, P., Aguayo, D., Clapp, C. \& Grosvenor, C.E. (1978) A rise in intramammary pressure follows electrical stimulation of mammary nerve in anesthetized rats. Endocrinology 103, 1929-1936.

Merchant, J.C. (1976) Breeding biology of the agile wallaby, Macropus agilis (Gould) (Marsupialia: Macropodidae) in captivity. Aust. Wildl. Res. 3, 93-103.

Montagna, W. \& Macpherson, E.E. (1974) Some neglected aspects of the anatomy of human breasts. J. Invest. Dermatol. 63, 10-16.

Morris, J.F., Nordmann, J.J. \& Dyball, R.E.J. (1978) Structure-function correlation in mammalian neurosecretion. Int. rev. exp. Path. 18, 1-90.

Pickering, B.T. (1978) The neurosecretory neurone: a model system for the study of secretion. Essays Biochem. 14, 45-81.

Poulain, D.A., Rodriguez, F. \& Ellendorff, F. (1981) Sleep is not a prerequisite for milk ejection reflex in the pig. Expl Brain Res. 43, 107-110.

Renfree, M.B. (1979) Initiation of development of diapausing embryo by mammary denervation lactation in a marsupial. Nature, Lond. 278, 549551.

Robinson, J.E. \& Short, R.V. (1977) Changes in breast sensitivity at puberty, during the menstrual cycle, and at parturition. Br. med. J. 1, 1188-1191.

Rossier, J., Battenberg, E., Pittman, Q., Bayon, A., Koda, L., Miller, R., Guillemin, R. \& Bloom, F.E. (1979) Hypothalamic enkephalin neurones may regulate the hypophysis (neuro). Nature, Lond. 277, $653-655$.

Russell, J.A., Harrison, D.J. \& MeNeilly, A.S. (1981) Bromocriptine and $\alpha$-ergocryptine do not inhibit oxytocin secretion in the lactating rat. J. Endocr. 89, 91-98.

Sala, N.L., Luther, E.C., Arballo, J.C. \& CorderoFunes, J.C. (1974) Oxytocin reproducing reflex milk ejection in lactating women. J. appl. Physiol. 36, 154-158.

Sharman, G.B. \& Pilton, P.E. (1964) The life history and reproduction of the red kangaroo, Megaleia rufa. Proc. zool. Soc. Lond. 142, 29-48.

Shaw, F.D. \& Morris, J.F. (1980) Calcium localization in the rat neurohypophysis. Nature, Lond. 287, 56-58.

Simantov, R. \& Snyder, S.H. (1977) Opiate receptor binding in the pituitary gland. Brain Res. 124, $178-184$.

Sofroniew, M.V. (1980) Projections from vasopressin, oxytocin and neurophysin neurones to neural targets in the rat and human. J. Histochem. Cytochem. 28, 475-478.

Soloff, M.S., Alexandrova, M. \& Fernstrom, M.J. (1979) Oxytocin receptors: triggers for parturition and lactation? Science, N.Y. 204, 1313-1315.

Summerlee, A.J.S. \& Lincoln, D.W. (1981) Electrophysiological recordings from oxytocinergic neurones during milk ejection in the unanaesthetized lactating rat. J. Endocr. 90, 255-265.

Theodosis, D.T., Dreifuss, J.J., Harris, M.C. \& Orci, L. (1976) Secretion-related uptake of horseradish peroxidase in neurohypophysial axons. J. Cell Biol. 70, 294-303.

Tindal, J.S. (1978) Central pathways in oxytocin and prolactin release. In Physiology and Mammary Glands, pp. 305-322. Eds A. Yokoyama, H. Mizuno \& H. Nagasawa. University Park Press, Baltimore.

Tribollet, E., Clarke, G., Dreifuss, J.J. \& Lincoln, D.W. (1978) The role of central adrenergic receptors in the reflex release of oxytocin. Brain Res. 142, 69-84.

Tyson, J.E., Friesen, H. \& Anderson, M. (1972) Human lactational and ovarian response to endogenous prolactin release. Science, N.Y. 177, 897-900.

Voloschin, L.M. \& Dottaviano, E.J. (1976) The channeling of natural stimuli that evoke the ejection of milk in the rat. Effect of transections in the midbrain and hypothalamus. Endocrinology 99, 49-58.

Voloschin, L.M. \& Tramezzani, N. (1979) Milk ejection reflex linked to slow-wave sleep in nursing rats. Endocrinology 105, 1202-1207.

Vorherr, H. (1971) Catecholamine antagonism to oxytocin-induced milk-ejection. Acta endocr., Copenh., Suppl. 154, 5-38.

Vorherr, H., Kleeman, C.R. \& Lehman, E. (1967) Oxytocin induced stretch reaction in suckling mice and rats: a semi-quantitative bioassay for oxytocin. Endocrinology 81, 711-715.

Wakerley, J.B. \& Deverson, B.M. (1975) Stimulation of the supraopticohypophysial tract in the rat during suckling: failure to alter the inherent periodicity of reflex oxytocin release. J. Endocr. 66, 439-440.

Wakerley, J.B. \& Drewett, R.F. (1975) The pattern of suckling in the infant rat during spontaneous milkejection. Physiol. Behav. 15, 277-281.

Wakerley, J.B. \& Lincoln, D.W. (1971) Intermittent release of oxytocin during suckling in the rat. Nature, New Biol. 233, 180-181.

Wakerley, J.B. \& Lincoln, D.W. (1973) The milkejection refiex of the rat: a 20 - to 40 -fold acceleration in the firing of paraventricular neurones during oxytocin release. $J$. Endocr. 57, 477-493. 